Tetrahedron Letters No.49, pp. 4941-4944, 1967. Percamon Press Ltd. Printed in Great Britain.

\title{
CONVERSION OF CYCLOPROPYL BROMIDES TO CYCLOPROPYLOXY DERIVATIVES
}

Daniel T. Longone and Alfred H. Miller

Deparument of Chemistry, The University of Michigan

Ann Arbor, Michigan 48104

(Received in USA 8 August 1967)

We report the first synthetically useful conversion of cyclopropyl halides to the corresponding cyclopropyloxy derivatives. The method developed utilizes cyclopropyl carbanions, derived from the bromides, as agents for nucleophilic attack on the oxygen atom of an appropriate substrate. Such reversal of the normal nucleophilic and electrophilic roles of the atoms involved obviates the difficilties inherent in the orthodox $s_{N} 1$ and $s_{N} 2$ reactions of the halide and allows for a net nucleophilic substitution.

Treatment of cyclopropyl Grignard reagents with benzoyl peroxide or $\underline{t}$-butyl perbenzoate affords the corresponding cyclopropyl benzoates and t-butyl ethers (I), respectively:

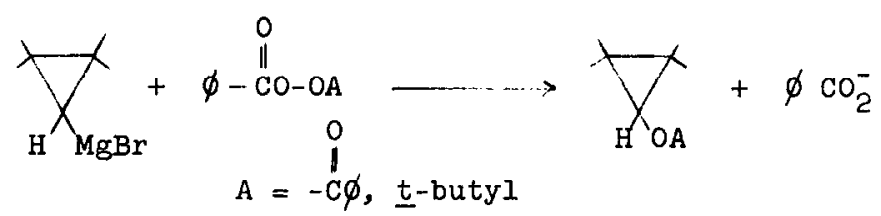

The t-butyl ethers are particularly useful because they are converted in high yields to the corresponding acetates by reaction with acetyl bromide, acetyl fluoroborate or acetic anhydride/ $/ \mathrm{BF}_{3}$-etherate. The last reagent is convenient to use and provides optimum yields of acetates under mild reaction conditions.

The yields (2) of t-butyl ethers range from 20 to $60 \%$ (see TABLE). 
TABLE

Yields of t-Butyl Ethers ${ }^{a}$

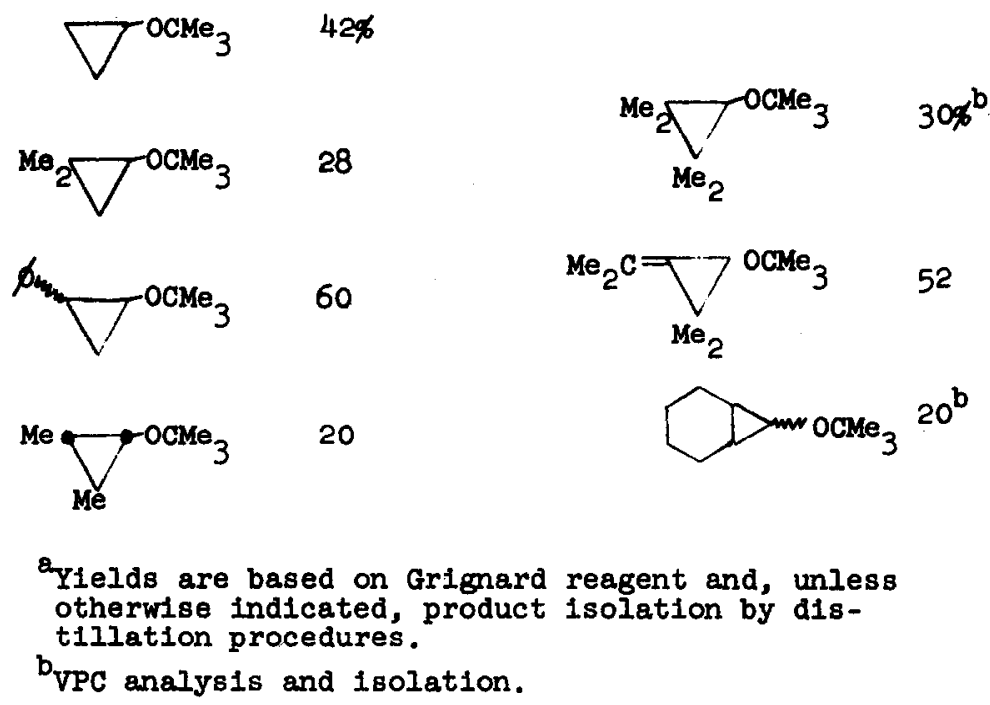

An example of the experimental procedure utilized is the preparation of cis- and trans- 2-phenylcyclopropyl t-butyl ether (from the corresponding mixed bromides) and subsequent conversion to acetates. To a solution of 0.13 mole of the Grignard reagent in $200 \mathrm{ml}$ of tetrahydrofuran was added, over a $10-\mathrm{min}$ period, $19.4 \mathrm{~g}(0.100 \mathrm{~mole})$ of $\underline{\mathrm{t}}$-butyl perbenzoate in $20 \mathrm{ml}$ of tetrahydrofuran. The reaction medium was held at -10 to $-5^{\circ}$ during the addition and then at $0^{\circ}$ with stirring for an additional $2 \mathrm{hr}$. Saturated ammonium chloride solution was added to dissolve all salts, the aqueous layer extracted with ether and the combined ether phases washed with dilute base, dried, and concentrated. Fractional distillation gave $4.0 \mathrm{~g}$ of phenylcyclopropane and $11.2 \mathrm{~g}(59 \%)$ of c1s- and trans- 2-phenylcyclopropyl t-butyl ether. The ether (1.2g) was treated with $3 \mathrm{ml}$ of acetic anhydride and $100 \mu \mathrm{l}$ of $\mathrm{BF}_{3}$-etherate at room temperature. After $2 \mathrm{hr}$ the system was 
quenched with dilute $\mathrm{NaOH}$. The ether extract afforded $1.0 \mathrm{~g}(90 \%)$ of cisand trans-2-phenycyclopropyl acetate. In a similar manner and in comparable ylelds, the requisite t-butyl ethers gave cyclopropyl, 2,2,3,3tetramethylcyclopropyl and 2,2-dimethylcyclopropyl acetates.

The reaction of cyclopropyl Grlgnard reagents with benzoyl peroxide affords the cyclopropyl benzoates in low yields $(<20 \%)$. For this reason the preparation of the acetates via the $\underline{t}$-butyl ethers is the prefered route to tra esterified cyclopropanols. Cyclopropanols are readily obtalned from the acetates by reductive cleavage with methyllithium or lithiun aluminum hydride (3). The reactions reported here and the availability of structurally diverse halocyclopropanes provide an attractive general route to cyclopropanols.

The reactions of cyclopropyl Grignard reagents with benzoyl peroxide and $\underline{t}$-butyl perbenzoate probably occur by other than a free radical pathway. A reasonable cyclic mechanism has been proposed for the related reactions of other Grignard specles with these substrates (4):

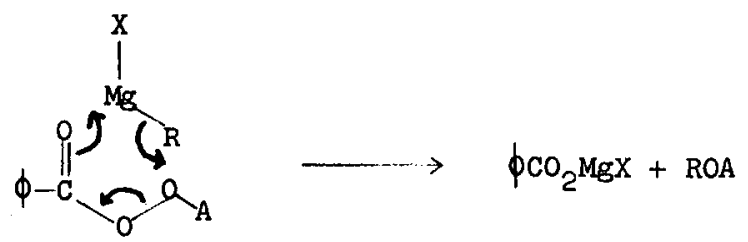

Mechanistic and stereochemical considerations are currently being examined.

ACKNOWLEDGEMENT: We are grateful to the National Institutes of Health, U. S. Public Health Service for support of this work through grant HDOI807.

\section{REFERENCES}

1. All compounds in this paper have been fully characterized by elemental analyses and infrared and $\mathrm{nmr}$ spectroscopy. 
2. We have not yet made a careful study of the effect of reaction conditions on product yields. Several tertiary cyclopropyl halides, exo- and endo- 7-chloro-7-phenylbicyclo [4.1.0.] heptane and 1-chloro-1-phenyl-2,2,3,3-tetramethylcyclopropane, falled to give cyclopropyloxy derivatives.

3. Cf. C. H. DePuy, G. M. Dappen, K. L. Eilers, and R. A. Klein, J. Org. Chem., 29, 2813(1964).

4. S. -O. Lawesson and N. C. Yang, J. Am. Chem. Soc, 81, 4230(1959). See also, S. -0. Lawesson, C. Frisell, D. Z. Denney, and D. B. Denney, Tetrahedron, 19, $1229(1963)$. 